JOURNAI, OF MENTAL SCIENCE, OCTOBER, 193.

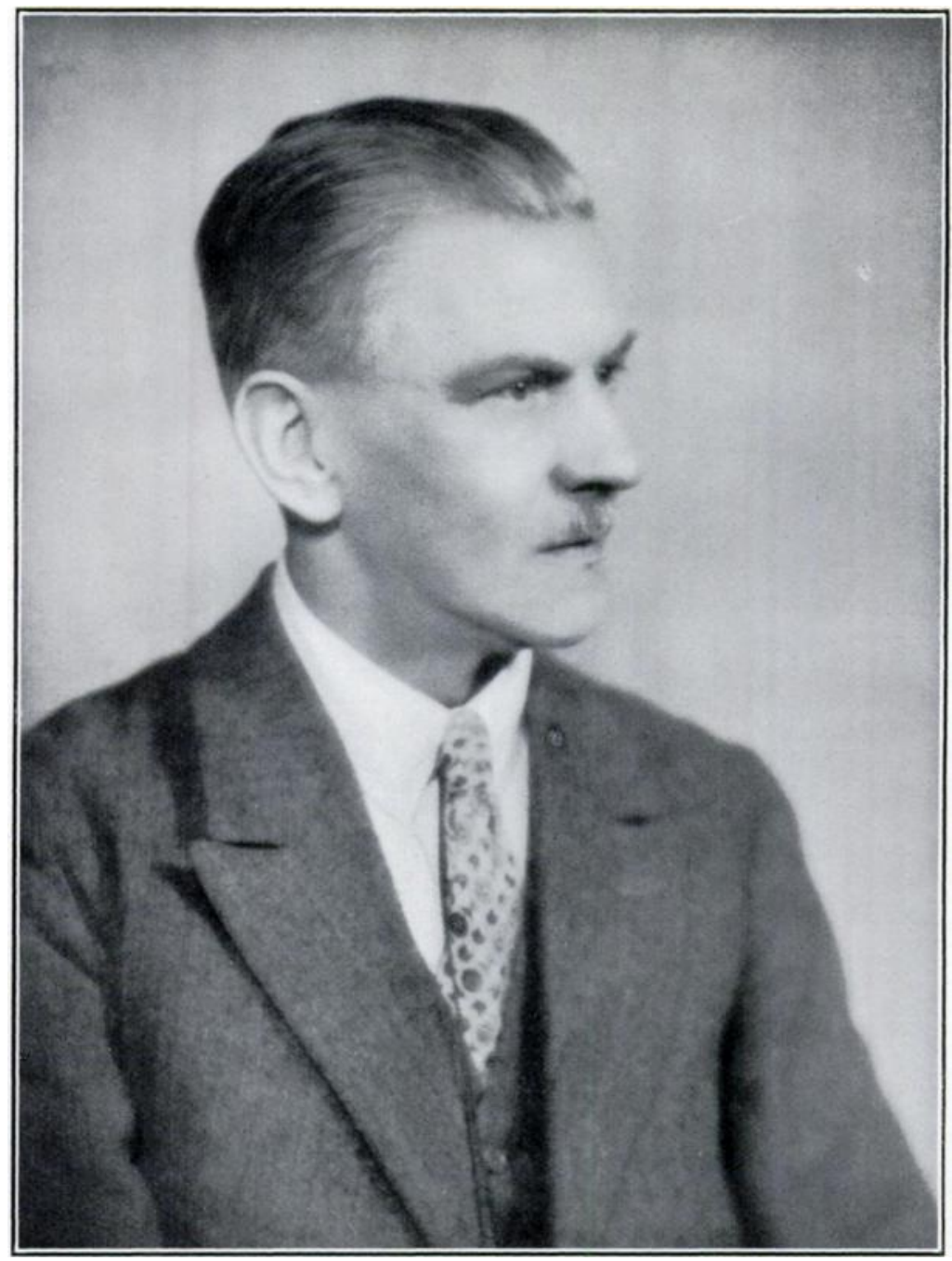

Photo Claude Harris.

JoHN ROBERT LORD, (.B.E., M.D., F.R.C.P.E., L.t.-Col. R.A.M.C.

Born August 14,1874 . Died August 10, 19.31.
Ordinary Member, 1898.

Co-Editor, Fournal of .Hental Science, 1911-31: Assistant Editor, $1900-1$

President, 1926-2 $\%$. 


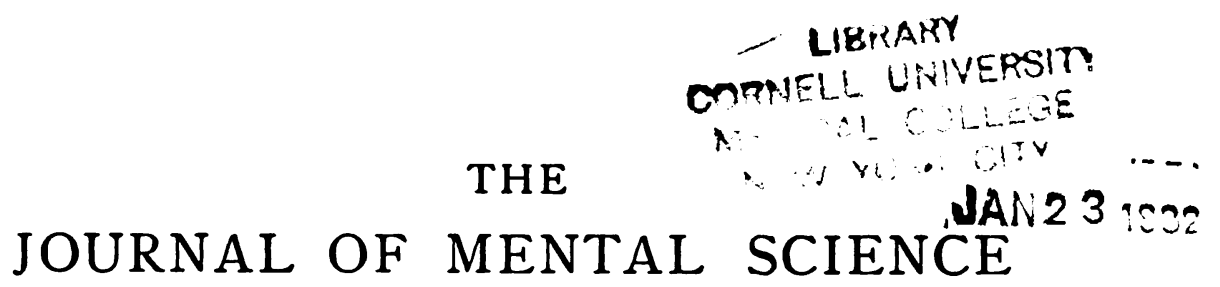

[Published by Authority of the Royal Medico-Psychological Association.]

\begin{tabular}{|c|c|c|}
\hline 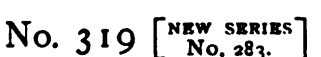 & OCTOBER, I93I. & Vol. LXXVII \\
\hline
\end{tabular}

\section{JOHN ROBERT LORD, C.B.E., M.D., F.R.C.P.E.}

By the passing, on August 9 last, of Dr. J. R. Lord, the Fournal of Mental Science loses its senior Editor, and the Association one of its most active leaders and devoted workers. No man gave himself more unstintingly to its work, or to the cause of psychiatry in so many of its aspects.

He was born in August, 1874, at Blackburn, and was educated there and at Owen's College, Manchester. Whilst still a youth we find him contributing articles to the Blackburn Standard, on such matters as "The Temperance Question," "Our Free Libraries and Museums and their Uses," and "Religious Toleration." His professional education was obtained at Edinburgh University, where he secured class-honours in several subjects, and was bronze medallist in General Pathology. He acted as Junior Demonstrator in Pathology at Surgeons' Hall. Whilst at Edinburgh his literary proclivities found expression in various contributions to Science Gossip. His final examination at Edinburgh was taken "with distinction" in 1896.

Lord's introduction to psychiatry took place in 1897 , when he became Clinical Assistant to Dr. Edwin Goodall at the Joint Counties' Mental Hospital, Carmarthen. From the first he was regarded as a youth of promise. Remarkable at that early date were the following traits: keenness, initiative, self-confidence, abounding energy, love of work, great powers of application, strong sense of duty, fairness of mind, kindness to all and sundry. Here, evidently, was a youth of parts, active-minded and ambitious. The ordinary routine work he took in his stride, and did well, but that was by no means sufficient. He devoted himself eagerly to the medical investigative work which was in progress. He not only collaborated, but had bright and refreshing ideas. He was awarded the Bronze 
Medal of the Medico-Psychological Association for work done at and about this period.

In 1898 Lord went with a strong recommendation to Hanwell, and so commenced his very successful and useful career in the service of the London County Council. Shortly afterwards he was appointed to Bexley, then the newest of the London county mental hospitals. The hospital had only been partially opened; only a few of the wards or pavilions were completed, sufficient for about 300 of the 2,000 beds for which the institution was being erected; and it was dependent on temporary and makeshift arrangements for its supplies of water, gas and electricity, as well as its cooking and its laundry. Such temporary expedients, while naturally tending to militate, for the time being, against high standards of medical work, call for efforts that both test and, in juniors, develop administrative capacity, and afford an experience that, in a variety of ways, is not without its subsequent value.

When Lord joined the staff at Bexley, the Medical Superintendent was Dr. T. E. K. Stansfield, from whom, as his Chief for close upon eight years and as he himself of ten testified, he derived much administrative wisdom and many an inspiration that stood later on in good stead; and the Deputy Superintendent was Dr. Hubert Bond, whom he succeeded in June, 1903. It is ever a hard thing to unravel and to distinguish which part of a man's character, actions and policy is derived from inborn qualities, and which from surroundings, and especially from the personalities of those with whom early professional training has brought contact. Certain it is that Lord's capacity and success were far from being mainly derivative.

From the first a diligent and thoughtful reader of contemporary psychiatric literature, and ready to assist in annotating, epitomizing and reviewing articles, it was during this period-to be exact, in 1900-that he, along with Dr. James Chambers, became an Assistant Editor of the Fournal of Mental Science.

It was out of his initial efforts on behalf of the Journal, and the reading which they necessarily involved, that he quite early-as the one of us who was with him at Bexley well remembers-was impressed with the value of Kraepelin's method of classifying mental disorders, of which most of us in this country at that time had only an imperfect acquaintance; the grip and understanding which he acquired of the subject, and his ability to diagnose cases by this-as one may term it-longitudinal mode of classification, were of great service to his colleagues. 
He it was who was in charge of two of the male sick wards when it was decided that their nursing should be entirely by women nurses. In the wisdom of this policy, the first occasion of its adoption in the London mental hospitals, his chief was a strong believer; but there were difficulties to overcome, some of them, as subsequent experience has shown, being in the nature of "bogeys." The present point is, however, not the system itself, but Lord's enthusiasm for what at the time was something of an innovation; an enthusiasm that later on could always be counted upon in aid of progressive achievements, and which supplied him with much of the pioneer's spirit.

Even during those Bexley days Lord's health was far from robust, and, though by no means an invalid, he was glad at times to seek the seclusion of his senior colleague's house, and to do some of his work on the sofa in the latter's study. Although he did not say so, it was probably because he felt physically disinclined or unable that he joined in none of the outdoor games or in the dances. Certainly he did not lack social inclination; indeed, quite the contrary; and while he did not take actual part in any of these amusements he was seldom absent from them, and delighted, on behalf both of patients and staff, in taking his share in their arrangements. He was fond, too, of music, and always ready to join in with a song or to contribute one to a programme.

Horton Mental Hospital had been opened in 1902, and, following a brief interregnum of some three months in its history, during which, as an emergency measure, Dr. Stansfield was seconded as its Superintendent, Lord was appointed to that position in February, 1907. It was not at that date an easy post to fill, and in the hands of some men might have proved rather their undoing than their success. With Lord, however, fortunately for him, for Horton, and for the many "causes" which he later espoused, it was otherwise. Of kindly and hospitable nature, strongly imbued with a sense of justice towards his staff, individually and collectively, taking a deep interest in his patients, amounting, as he not so long ago confessed, to a great affection for them, and intent on the development of all fruitful measures for their treatment, such difficulties as remained were soon dissipated; and, with a staff bent on seconding his efforts, and a committee whose confidence and support he had firmly secured, Horton quickly became well known for the excellence of its medical administration, and as one of the most progressive mental hospitals in the country.

At Bexley, pioneer work had been in progress in the direction 
of introducing better facilities for the study and treatment of recent cases by the provision of admission and convalescent units. In this work Lord had taken his full share and, in entire sympathy with its principles, he saw to it that not less good facilities should exist at Horton; the new admission hospital there, for males, which was opened in 1912, was largely of his own planning. Laboratory work was developed; and conspicuous among Horton's many advances were its arrangements for the occupation of its patients ; not, however, in those days on the lines which we nowadays call occupational therapy. It was rather the institution and great extension of trades, and the creation of a veritable hive of industry on the lines which had been developed at Bexley, especially by his colleague Dr. P. T. Hughes. The repute of Horton waxed high, and deservedly so.

Then came the war, and, as one of its myriad incidents, the scheme inaugurated by the Board of Control under which twentyfour mental hospitals became war hospitals; a few of them to serve as special hospitals for neurological and mental cases, but most of them for the reception of sick and wounded of all types. This scheme, both during and after its operation, without doubt has exerted a powerful influence, mostly for good, upon the administration, especially in its medical aspects of British mental hospitals, and in various ways, to explain which would be out of place here, has done much to bring their work into closer touch with general medicine ; indeed, the force of its after-effects is not yet spent.

Among the mental hospitals earliest selected for this purpose was Horton, and from May, 1915, to October, 1919, Lord was its Officer Commanding with the rank of Lieutenant-Colonel in the R.A.M.C. Denied from serving overseas, both by his health and by his holding a position from which he could not be spared, there is no doubt that, despite its arduous nature and the heavy strain, mental and bodily, which it threw upon him, and despite the difficulty of exchanging a civil for a military discipline-which, as events proved, was beyond the capacity of some men-to Lord this opportunity of rendering war service came as a real solace and relief. How gladly and easily he took to these duties may possibly in some measure be related to the volunteer work which he did during his Edinburgh days in the University Battery of the Edinburgh City Artillery, and as a Lieutenant in the Edinburgh Battalion of the Boys' Brigade.

Into this great undertaking he threw his whole energies with the utmost enthusiasm, and he had the satisfaction of knowing, as 
likewise did his Committee, that the "Horton (County of London) War Hospital " was one of the best and most efficient in the country. Its activities figure in official records, and its "Story" has been told in a book written by himself and published in 1920. Let it suffice here to say that to this large war hospital, the capacity of which varied from 2,040 to 2,532 beds, the total number of military patients, including a certain number of naval ratings, admitted was 44,623 .

Throughout the whole of the military occupation of Horton, Lord's stimulating energy, backed by a most zealous staff, was prodigious. Nothing seemed to please him better than a suggestion or request for the concentration of this or that service at his hospital; nor did the trouble or re-adaptations which these "extras" necessarily involved ever in the least daunt him.

For his war-hospital services, Colonel Lord was in 1918 created a C.B.E. (Military Division).

Lord's war-hospital activities-they were necessarily much wider than the hospital's intramural duties-and the many considerations that had to be taken on the closing down of the institution's military occupation and its return to civilian functions, had a noticeable effect on his outlook upon psychiatry. By no means was it a mere reinstatement of the hospital to its civilian use.

It was in truth reconstruction rather than reinstatement, and a retention of every facility which, installed for war-hospital purposes, a broadened outlook saw to be required equally for the multifarious needs of mental cases; that is, if the institution really were to deserve the name "hospital."

It is beyond our available space to set out in full the developments introduced at Horton under Lord's régime. A bare mention must suffice of such matters as the great increase in the system of parole given to patients; the extensive development of X-ray work and of treatment by ultra-violet radiation; and the development of occupational therapy in its modern and more specifically remedial form. Malarial treatment of general paralysis was taken up at an early date, and a laboratory and centre were established, in conjunction with the Ministry of Health and the Board of Control, in which valuable research work has been carried out not only on general paralysis, but on the treatment and prevention of malaria itself. Another direction in which Lord was very solicitous was the all-round adequacy of the patients' dietary. It is the belief of most of his colleagues that the almost entire eradication of dysentery has been largely due to improvements in the dietary scales. 
Lord was a strong advocate of team work in mental hospitals, especially in dealing with recent mental cases. By specialization on the part of the medical staff, and by the employment of consultants, he sought to bring every branch of medicine to bear on each individual case. The spirit of his hospital has been well described as "polypragmatic." It was his pride that no form of investigation or treatment, physical or psychological, was neglected at Horton.

He was, from the first, impressed with the necessity of enlightening the community on the problems of mental disease. "Mental Hospitals and the Public-a Plea for Closer Co-operation" was not only the title of one of his publications, but was the keynote of much of his work. His hospital was among the first, if not indeed actually the first, to appoint a social worker to link it with the outside world. Another step in the same direction was the establishment of a firm link between Horton and the Royal Free Hospital and its School of Medicine for Women. Since 1928 he was Lecturer in Clinical Psychiatry to the School, and he organized at Horton a course of instruction of unusual thoroughness. He welcomed visitors to his hospital, especially parties of educational or psycho. logical students. The Mental Hygiene movement found in him a warm supporter. From 1923 onwards he was Honorary Secretary of the National Council for Mental Hygiene, and he spoke and wrote extensively on its behalf.

His early association with the Journal has already been mentioned. He became joint Editor in I9II, and from I9I4 onwards as senior Editor, he carried on not only the general direction of the Journal, with the voluminous correspondence this entailed, but also a great mass of detailed and routine work. Besides his more important contributions, of which a list is appended, there have been few numbers of the Journal during the last twenty years that have not contained some editorial notes or reviews from his pen. He took particular pains over his reviews, many of which he expanded into essays of considerable intrinsic value.

His interest in the activities of the Royal Medico-Psychological Association, apart from the Journal, also dates from early in his career. He soon made a mark, with his ability, enthusiasm, industry and determination, and for long years, and up to the time of his death, he was a leader in the work of the Association. $\mathrm{He}$ had its interests constantly at heart, and did everything in his power to maintain and add to its prestige and dignity. He rendered great service in preparing evidence for the Royal Commission on Lunacy, and it was largely owing to his efforts that the Association 
obtained its charter of incorporation, and the designation " Royal." His services were recognized in 1926 by his election to succeed Sir Frederick Mott as President.

At that time-in fact since the end of the war-his health had already begun seriously to fail, and he was burdened by a constant struggle with recurring illness. No one ever put a braver front on ill-health, or more serenely ignored its disabilities. He cheerfully complied with such restrictions in matters of diet as were enjoined upon him; and the fact that he seemed to require less sleep was accepted almost gladly as the provision of opportunity to get through more work.

The one matter upon which he was disobedient and deaf to all persuasion was in relation to any attempt to induce him to stop work or to slacken its output ; and, as Professor G. M. Robertson truly stated in the course of his graceful tribute to Lord's work in the British Medical Fournal of August 22 last, " Every evening, however, after his official duties for the day were over, he began a second day's work for the Association, working on till all hours of the morning of the next day. The amount of work, mainly of a literary and organizing kind, that he did during these undisturbed hours in the evening and the night-time was colossal."

Consequently, when his name was put forward as President-Elect of the Royal Medico-Psychological Association, there was considerable doubt whether he would feel able to accept the position, and a fear that, if he did, the further claims upon his energies during his actual year of office as President would react adversely on his health. Quite otherwise was the event, and, just as his war-hospital duties had seemed to release a reservoir of pent-up energies, so the offer of this honour and his decision to accept it, besides giving him keen delight, seemed to tap yet another well of energy. His proceeding, during his preparatory year as PresidentElect, to his M.D. degree and to the membership of the Royal College of Physicians in Edinburgh-who immediately conferred their Fellowship upon him-was something of a feat; and during his year in the chair he was Vice-President of the Section of Mental Diseases of the British Medical Association; while his activities, attendances at meetings and committees were unremitting, and the fertility of his suggestion was remarkable.

His presidential address on "The Clinical Study of Mental Disorders" was a wide survey of contemporary tendencies in psychiatry, as well as containing a detailed programme of hospital team-work. During his year of office, and mainly at his instigation, 
the Research and Clinical Committee came into being, over which he presided, taking the liveliest interest in the work of its various sections. The detailed reports of the Committee, which became a feature of the Association's annual meetings, were from his hand, and each year he was able to record valuable scientific results from its labours.

In the years following his presidency, Lord, with the Research Committee added to his duties as editor, was already doing more in the service of the Association than ever before; but he cheerfully undertook yet further tasks. He shared to a considerable extent in the work of the General Secretary, and, in the latter's enforced absence, several times acted for him at annual meetings. He was as active as ever in medico-political and educational work. He gave much assistance in connection with the Mental Treatment Act. His study of the "Evolution of the Reception Order" did much to elucidate the true purpose of judicial intervention in mental treatment, and facilitated the abolition of such intervention in non-volitional cases. The training and registration of mental nurses was another subject to which he gave much attention, and he devoted time and energy in every endeavour to uphold the status of the Association's nursing certificate. In 1929 he was appointed a member of the General Nursing Council.

His opinion and advice were often sought in such matters as the organization and staffing of psychiatric services overseas. His work brought him in touch with many foreign psychiatrists, and he was an associate member of several medico-psychological societies abroad. Last year he attended the first International Congress of Mental Hygiene at Washington, as representative of the London County Council and of the Association. He presided at several of the sessions, and was elected a member of the permanent committee. At the conclusion of a most strenuous fortnight, he spent his time during the return voyage in writing out a full account of the Congress, with reflections on American psychiatry, which he read to a quarterly meeting of the Association on the day following his arrival.

No memoir of Lord could be complete without some reference to his vivid and striking personality. The following lines of personal appreciation are a record of the impression left by him upon one who knew him well from his Bexley days onward:

There was something a little flamboyant about John R. Lord. He faced life, especially in his earlier years, with an air; even his dress proclaimed it; the task of clothing himself, like everything else 
which he undertook, was performed with complete thoroughness, and yet a spice of adventure entered into the performance, as it did into such matters as the cut of his hair or the wearing or not of a beard. The same tendency showed itself in his love of ceremonial, which made him an ideal public orator and master of ceremonies at Association meetings, and made him delight in the designing of the Association's coat of arms and its medals and badges. All that he did, he did intensely and with a zest, and he found, one believes, in spite of the chronic ill-health of his later years, immense enjoyment in life and what it brought him. He lived his life thoroughly and to the full; even from his illness he seemed able to draw a curious interest that was almost a recompense. His tremendous appetite for work was a case in point; his life for many years as a bachelor medical superintendent was, in some respects, an isolated one, and his work absorbed energies which might have found scope elsewhere. Work to him was never an uncongenial burden; he revelled in it, and in its pursuit willingly turned night into day. In the years after 1918 one felt that his work, carried on as it was in face of tremendous disabilities of invalidism, really helped him to survive; the need for concentration upon other things kept his busy mind employed outside the ailments which in a man of less exuberant temper might have overmastered all else. He had, however, a dogged will-no one who ever worked with him could fail to realize that-and he was able to grapple successfully with difficulties before which a lesser nature would have sunk.

The fertility of Lord's mind was shown, not only in the ideas he himself originated, but in his characteristic and somewhat curious manner of receiving suggestions from others. One would approach him with some suggestion for change; his first reaction would be briskly negative - a dozen reasons to the contrary at once appeared. But his active brain was never contented with the first impression; the irritant idea would work and ferment, until presently the astonished and slightly amused propounder of the first crude hint would find himself presented with a fully organized scheme fortified with arguments and supported by precedents. "You know - . I have been thinking for some time that so and so might be done . . . don't you agree?" One soon learned that the best way to convince Lord was to leave him to convince himself.

Lord loved his life; it was to him so full of interest, so well worth living for the sake of what could be done with it. It is hard to realize now that that eager, questing spirit is stilled, so far as mortal 
relationships are concerned. $\mathrm{He}$ was necessarily rather a lonely man, yet a more essentially friendly spirit never breathed. He could be generous to a fault in his appreciation of other people's kindness to him, and he was kindness itself to his friends. One never asked him in vain for help which he could give.

He married, in March of this year, Dr. Ruby Thornton Carr, who was a member of the medical staff of Horton. It was with real gladness that his closest friends welcomed the marriage of affection which it seemed would bring a new delight and interest to his maturer life. But a few months of happiness was all that was granted to him, and the sympathy of all who knew him goes out to his widow in the very sad circumstances of her bereavement.

\section{Editorial Note.}

Dr. Lord's work was so extensive, and its ramifications so widespread, that it has been found impossible to give an adequate account of his life, activities and character in a notice written by a single author. The greater part of the present memoir is the work of Sir Hubert Bond, Dr. E. Goodall and Dr. A. Walk. The personal appreciation at the end was contributed by Mr. R. H. Curtis.

The following is a list of Dr. Lord's principal publications :

\section{Books.}

The Story of the Horton (County of London) War Hospital, 1920. Social Workers and the Insane, 1923.

The Clinical Study of Mental Disorders (Presidential Address), 1926.

Mental Hospitals and the Public: The Need for Closer Co-operation, 1926.

\section{Articles.}

(Most of these appeared in the Journal of Mental Science in the years indicated.)

1898. "The Collecting and Recording of Descriptive and Anthropometric Data of the Ear in the Neurotic, Insane and Criminal-a New Method."

"A New Nissl Method" (Bronze Medal and Prize Essay).

"Normal Structure and Morbid Changes in the Pineal Body."

"Types of Epilepsy."

"The Care of the Epileptic."

1909. "Obsessional and Impulsive Insanity."

1913. "Criminal Types in a County Asylum."

1920. " Progress of Psychiatry in England."

"The Nosology of Dementia Præcox."

"Ministry of Health (Miscellaneous Provisions) Bill."

1922. "General Improvements in Lunacy Administration, etc."

"The Trend of Psychiatry in England and Wales."

"Progress of Psychiatry in the Union of South Africa."

"The National Council for Mental Hygiene."

1923. "Lunacy Law and Institutional and Home Treatment of the Insane."

"Syllabus of Instruction for Probationer Nurses during their first Six Months' Service."

"Sir Frederick Mott."

"The Prophylaxis of Insanity, etc."

"The Administration of Public Mental Hospitals, etc."

"Chronic Sepsis and Mental Disease."

1924. "The Training of Nurses and Reciprocity between Mental and General Hospitals."

"Birth Control-A Critical Review." 
1925. "The Royal Commission on Lunacy and Mental Disorder."

"The Law Relating to Lunacy."

" Epilepsy : A Clinico-Pathological Study of Fifty Cases."

" Psychiatry, Legal and Administrative, in some European Countries and in

America." (Evidence before Royal Commission on Lunacy.)

1926. "The Foundation of the Royal Medico-Psychological Association."

"Some Psychological Reflections."

" Phillippe Pinel (1745-1826)."

1927. "The Association's Coat of Arms."

" John Coakley Lettsom and Psychiatry."

"The Induction of Abortion in the Treatment and Prophylaxis of Mental Disorder."

“The Evolution of the Reception Order for Mental Patients : A Historical Survey."

1929. "The Evolution of the "Nerve' Hospital as a Factor in the Progress of Psychiatry."

“ A Modern Approach to the Problem of the Admission of Mental Patients to In-Patient Treatment."

"The Local Government Act and Administrative Psychiatry."

1930. "American Psychiatry and its Practical Bearings on the Application of Recent Legislation: Including a Dscription of the First International Congress on Mental Hygiene."

"Psychology, the Science of Mind."

"After-Care and other Aspects of Social Service as an Adjunct to Mental Treatment." 